\title{
Reflection on Application of Sports Games in P. E. Education
}

\author{
Li Qin
}

Nanchang Institute of Science \&Technology,Nanchang 330108,China

Keywords: Physical education; sports game; P. E. curriculum

\begin{abstract}
Through literature analysis and practical experience, this paper gives a discussion on the rational use of sports games in physical education, discusses how to select and what should pay attention to when use sports games in the process of sports teaching, in order to better play the sports game's value and effect, serving for sports teaching .

The sports game plays an important role in the sports teaching, it plays an irreplaceable role, it is the main means of physical education and an important part, it is the main way to complete the task of teaching and training tasks, the use of sports games in physical education teaching, enthusiasm and initiative can not only mobilize students to participate in sports teaching. But also can develops of student's personality, improve physical fitness and sports skills training, unity, love the collective and law-abiding qualities, so, how to choose and use of sports games and the matters which had to be paid attentionis very important in the process of physical education. This paper makes some rational thinking and analysis on the application of sports games in physical education, in order to give full play to the value and effectiveness of sports games.
\end{abstract}

\section{Essential characteristics of sports games}

The sports game is a branch of the game,it is a form of physical activity, so it has the general character in addition to games and sports activities, as well as it has its own essential characteristics, such as education, ineffective, entertainment, competition, collective, rules, social fairness, etc.. In order to effectively play and value of sports games in physical education, it must be based on the following sports teaching law, to fully understand and grasp the essence and characteristics of sports games, so as to better play the function and value of sports games.

Educative. The psychological quality and sports skill application of sports games in the classroom teaching and training can make students better development of students in the cheerful, fierce and tense atmosphere; so that students can see the outcome in a relaxed state of mind; students can cultivate honest, courageous, strong, smart personality, excellent quality and compliance discipline, solidarity, collective concern; can cultivate students' observation, memory, judgment; can make students more active thinking, sense organs and organs developed more agile; ability training and improving students' ability to understand, accept and solving problems capability.

Entertainment. No matter what type of games, the game is to play, so the sports game, participants participate in a relaxed, free and equal manner, get a free expression in a relaxed mood, so as to meet the need for their physical, psychological and social emotional, pleasurable emotional experience.

Competitive. Sports games, like sports, are competitive and exciting, although the outcome of games, win or lose, but the game activity is not the purpose of the results, but the process of activities, justice fairness and power distribution activities in the game, the referee penalty, set equal chance and uncertainty as the outcome of the game, any little mistake and poor play are likely to 
defeat in the competition, winning the equality of opportunity and uncertainty; on the one hand, to stimulate the enthusiasm of students to participate in the game, on the other hand, it also strengthened the competitive games.

Fairness. The sports game is a non-competitive race, it has certain regularity and randomness, the rule set although only in the game, do some schematic description and definition, but this does not mean that the sports games participants can free from game rules, does not mean that the organizers can freely decide. In the game, the referee should be fair and impartial, lack of fairness of the ruling, affecting the enthusiasm of the participants will, will destroy the harmonious, friendly and pleasant atmosphere, the fairness is reflected in the following five aspects: First, the fairness of the referee penalty; two is the relative fairness of the participants' strength; three is the equal opportunity for the participants to play the role; four is the equal opportunity for the participants to obtain the competition; five is that the participants have the equal opportunity to win.

Regularity. There are rules of the game, the rules of the game to participate in the game when the game is binding on the players, there is no rule of the game does not exist. on the other hand, the game does not depend on the rules. The rules of the game is not immutable and frozen, making is not very detailed, so in the use of the game, it should be taken into consideration in object, site conditions, equipment and other factors of different formulation and transformation rules of the game.

Collectivization. Sports games are both individual and collective, but more of a collective project. In the game, the player has the relative freedom of individual activities and the unity of the collective strength. The player in the game in the process of technology, personal skills need to be integrated into the collective power, a temporary interest groups, solidarity and cooperation, joint efforts, participation in the process of activities and enjoy the game in order to obtain the results of the activities of the victory of the game.

\section{Reflection on Application of Sports Games in P. E. Education.}

Interesting problems in the use of sports games. Sports game is an important means of physical education. It is an effective way to relax the body and mind, improve attention, eliminate fatigue and improve sports ability. It is difficult to form an effective centripetal force for the lack of interesting sports games, and can not arouse the enthusiasm of the players. In this way, the process of the game activities reflect the fun of the game, the game has become an important factor in the success or failure of the use of sports, so in the design of sports games in the fine, clever, odd up and down, to give it enough fun factor. The two is in the choice of sports games to have a taste of sports games teaching materials, many kinds of examples, we choose though the space is very large, but still want to consider to choose according to the specific teaching environment, site condition, students' comprehensive analysis, combining with the teaching practice, so as to achieve the desired teaching effect. Three is a sports game and game method to master a certain amount of distinction, understand common and difference of different sports, to integrate the innovation from the aspects of conception, composition, field and equipment, to meet the specific requirements of different teaching contents four sports game content basically comes from social life and daily in practice, so the creation and selection of sports games to be close to students' life situation and cultural environment.

The moderation of sports games. The sports game is a form of physical exercise, activities of the game is also a function of the body, either as a practice of physical education, or as a supplementary means of education and training, all need to grasp the use of sports games. The main features: one, sports games time should not be too long, otherwise it will make students have less interest and lose 
interest in sports games; Two is not too much to use individual teaching hours, this will confuse the emphasis and difficulty of learning, teaching content and even the game have the order reversed; Three is to arrange the amount of sports games to moderate, can not make the students into the fatigue of the important content of the course teaching, otherwise, it will affect the quality of physical education teaching and teaching results.

The application of sports games .The application of a wide range of sports games, more competitive and confrontational, which can meet the needs of sports teaching and sports training, and can be carried out widely in the mass sports activities. But in the choice of sports and sports games scene setting, should give full consideration to the student's physical quality and skill level differences distinguish treat, for to select and design the sports game, at the same time, according to the different sports games, according to the different teaching objectives, requirements, the purpose, methods, rules and punishment of the game. It should be targeted as the emphasis is on the process of the game or the results, is the course of action, is the team spirit of cooperation or personal freedom ability, must be based on the change of the teaching task requirements vary.

On the fairness of sports games. The purpose of sports game rules is to ensure the smooth progress of the game. In the game, students can be allowed within the scope of the rules, creative activities. In the implementation process, according to the specific circumstances and requirements, effectively improving the contents and rules of the game, in order to improve the specific interest, so as to achieve the purpose of game teaching, reflect the fairness of the game activities: one is the referee to reflect the fair, the lack of justice, it will affect the mood of participants, destroy the harmony and friendly atmosphere, is not conducive to the conduct of the game; two is the group game before, according to the physical condition of students, technical ability, training level, make each strength approximately equal; three is the packet after each players have equal opportunities to participate the game activities, the role of equal opportunity, fully mobilize the enthusiasm of the students, so that students enjoy equal conditions and opportunities to participate in sport games.

The randomness of sports games. Sports games is a comprehensive form of activities, a variety of sports can become the content of the creation of sports games, a variety of common equipment can be cleverly conceived as a sports game. Therefore, as a supplementary means of physical education, training, or leisure entertainment, sports games have unique advantages. In the spare time and extra-curricular activities, the organization of sports games, will be boring, dull, monotonous teaching environment to add vitality.

The comprehensive problems of sports games. All mentioned here, the first refers to the all-round development of students, students' physiological and social adaptation of the three aspects of the overall development; second is a comprehensive game project, different types of games are involved in the selection of games. Not only have to reflect the individual skills, willpower, psychological and other factors, but also reflects the team spirit, team spirit and show good moral quality. More importantly, in accordance with the requirements of the syllabus, according to the characteristics of the development of students' physical and mental development and different stages of the development of students' physical quality, sports skills and the choice of different sports games. The relevance of sports games.

Sports games as auxiliary means in classroom teaching of physical education, the content and the form must be taken into account to guide and pave the way for the teaching content behind, so that there is a compact and complete teaching content, and will not appear in the main content of teaching, the students also immersed in the front of the game situation, attention the problem of fragmentation. The main purpose of the use of sports games is to effectively complete the task of teaching, so the design of the content must be linked with the teaching content, means to achieve 
continuity of teaching activities.

\section{Conclusion}

In the sports teaching, appropriate arrangements for sports games can active classroom atmosphere, enrich the teaching content, to stimulate interest in learning, improve teaching quality, promote students' physical, psychological and social adaptation ability of all-round development. So in the sports teaching, must be based on the correct understanding of the essential characteristics of sports games on the rational use of sports games, sports games with good treatment and precautions, with purpose, plan selection, organization of sports games, and constantly improve the quality and effect of the use of sports games, make it an effective means and important content of sports teaching.

\section{References}

[1]Chen F L, Tang J X, Tang J X. On education of innovation in sports games for P.E. majors[J]. Journal of Sports Correspondence, 2003.

[2]Sun Y L, Wang B, Zhou X J. Establishment and innovation of scheme for P.E.majors[J]. Journal of Wuhan Institute of Physical Education, 2011..

[3] Ho W, Higson H E, Dey P K. An integrated multiple criteria decision making approach for resource allocation in higher education[J]. International Journal of Innovation \& Learning, 2007, 4(5):471-486..

[4] Grischke E M, Wallwiener D, Souchon R, et al. Isolated Loco-Regional Recurrence of Breast Cancer - Established and Innovative Therapy Concepts[J]. Geburtshilfe Und Frauenheilkunde, 2013, 73(06):611-622..

[5] Schmidt G, Solomayer E F, Herr D. Electrochemotherapy in Breast Cancer: A Review of References.[J]. Geburtshilfe Und Frauenheilkunde, 2014, 74(6):557-562.

[6]Imanaka K, Sakaguchi T, Kodama A, et al. Radiotherapeutic Management of Isolated Loco-Regional Recurrence of Breast Cancer after Mastectomy.[J]. J Jpn Soc Ther Radiol Oncol, 2011, 6.

[7]Rutgers E J T. Tailored Surgery for Early Breast Cancer: Biological Aspects[M]// Breast Cancer and Molecular Medicine. Springer Berlin Heidelberg, 2006:183-198. 